\title{
EFFECTS OF CHRONIC DIELDRIN INGESTION ON THE MUSCULAR EFFICIENCY OF RATS
}

\author{
BY \\ MÉLÈK KHAÏRY \\ From the Medical Research Council's Group for the Experimental Investigation of Behaviour, \\ Psychology Department, University College, London
}

(RECEIVED FOR PUBLICATION SEPTEMBER 7, 1959)

Several cases of dieldrin poisoning were reported amongst sprayers following repeated exposure to this insecticide. The symptoms developed by some of the most severe cases of poisoning included epileptiform convulsions.

The effect of dieldrin on muscular efficiency of rats was studied. A state of chronic toxicity was produced by maintaining two groups of rats on a diet containing 25 p.p.m. and 50 p.p.m. of dieldrin respectively. A third group receiving a diet containing no dieldrin acted as a control. Muscular efficiency was measured by training the rats to pull weights of increasing magnitude in a $250 \mathrm{~cm}$. runway. The time taken to pull the weights through the standard distance was recorded.

Dieldrin appeared to have no effect on body weight, food intake, or learning, but muscular efficiency (as measured here) seemed to be affected by this compound. A progressive deterioration in muscular efficiency was observed, and was related to the amount of dieldrin administered. Although the nature of the deterioration cannot be deduced from this study, the results obtained here suggest possible lines of investigating the early effects on human beings of exposure to dieldrin.

The insecticide dieldrin has been used in numerous insect control programmes, giving highly satisfactory results. However, a number of cases of poisoning following repeated exposure to dieldrin have been reported amongst sprayers handling this compound (e.g., Carrillo, 1954; Patel and Rao, 1958). From the diverse symptoms described as following dieldrin poisoning, those associated with disturbances in the muscles ranged from twitching of the muscles in mild cases of poisoning to epileptiform convulsions, with loss of consciousness, in severe cases.

In view of these effects it was considered desirable to investigate the effects of dieldrin on the muscular efficiency of rats. Muscular efficiency was measured in terms of the ease with which trained rats could pull weights of increasing magnitude through a standard distance.

\section{Experimental Procedure}

Twenty-four male albino rats from the colony of the M.R.C. Toxicology Research Unit were used as subjects. The animals were randomly divided into three equal groups. The control group $\mathrm{C}$ received no drug. Experimental group $E_{1}$ received 25 p.p.m. dieldrin in the diet (M.R.C. diet 41B), and experimental group $E_{2}$ received 50 p.p.m. The dieldrin consumed was approximately equal to a daily amount of $0.125 \mathrm{mg} . / 100 \mathrm{~g}$. body weight and $0.25 \mathrm{mg}$. $/ 100 \mathrm{~g}$. body weight respectively. The special diets were kindly supplied by the M.R.C. Toxicology Research Unit.

From the age of 75 days the rats were started on their special diets. The groups were maintained on one hour feeding in each 24 hours. The diets of the animals and the feeding schedules were not changed throughout the entire experiment. The food intake of the three groups was checked daily and the animals were weighed regularly during the week.

The apparatus used in this experiment is shown in Fig. 1. The distance which the rats had to travel in the runway while pulling weights was $250 \mathrm{~cm}$. At one end of the runway was the starting point where the animal was introduced into the apparatus, and at the other end was a food tray. When in the runway the animal was observed through the transparent "perspex" wall which formed one of the sides of the apparatus. Observation was also possible through the lids of the runway which were made essentially of wire mesh which allowed the animal to be removed easily from any point on the runway. In order to translate the horizontal movement of the rat $(250 \mathrm{~cm}$.) into the vertical lifting of the weights $(50 \mathrm{~cm}$.) a system of two geared wheels was used. A 


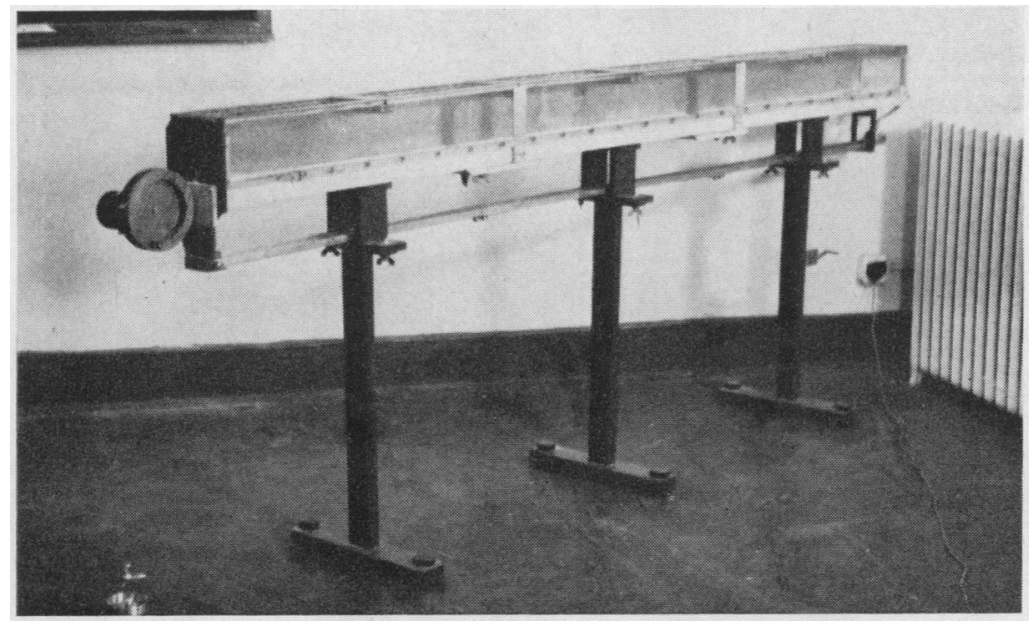

FIG. 1.-The apparatus.

"perlon" line was attached to a special harness worn by the rats, and as the rat moved from start to finish it unwound from the larger wheel. This movement of the large wheel caused the small one to rotate, resulting in the lifting of the tray containing the weights. The tray itself weighed $60 \mathrm{~g}$., but since this is constant for all animals it is not included in the figures for weights pulled by the animals. Similarly the slight friction in the system is ignored. Since there is a 5:1 ratio operating in the system it is possible to consider the rat's performance as corresponding to lifting one fifth of the weight in the tray through the full distance of $250 \mathrm{~cm}$. Scores used in the experiment will be expressed in this form.

The reward used during the training and testing of the rats was food, the animals having been deprived of access to food during the 23 hours preceding the experiment. In the apparatus the animals were given the same diet as that upon which they were maintained.

The training of the rats to pull weights was carried out in two phases. In the first phase each animal was put into the apparatus and allowed to explore and feed for five minutes each day for five days. During the second phase the animals were trained to run trials, and were accustomed to wearing a harness while running. Each rat was given nine trials a day. A learning criterion was adopted in order to get comparatively the same degree of adaptability to the harness throughout the sample of animals used in the experiment. A rat was considered as having learned when it made nine runs in a total time of 60 seconds or less on each of two consecutive days. The number of trials taken by each animal to reach the criterion was recorded.

When all the animals had reached the criterion, the rats were started on weight pulling, having been fed on their respective diets for 60 days. Each rat was now given 10 trials a day. From now on the rat's harness was attached to the "perlon" line and as the animal ran the length of the runway the weight tray was raised. On the first day the weight placed in the tray was $25 \mathrm{~g}$., which corresponded to the animal lifting $5 \mathrm{~g}$. through $250 \mathrm{~cm}$.
On the next day the animals were made to pull a weight corresponding to $10 \mathrm{~g}$. On the following and subsequent days a weight corresponding to $10 \mathrm{~g}$. was added to the weight previously in the tray. The time taken by the rat to complete a trial was recorded.

\section{Results}

There were no significant differences between the groups on body weight or food intake. Learning scores represented by the number of trials taken to reach the criterion are given in Table 1. A one-way analysis of variance (Kruskal and Wallis, 1952) showed that the differences between the groups were not significant, that is to say, for learning as measured here, there was no impairment or enhancement as a result of the administration of dieldrin.

TABLE 1

EFFECT OF DIELDRIN ON LEARNING

\begin{tabular}{c|c|c|c}
\hline \multirow{2}{*}{ Group } & \multirow{2}{*}{ No. of Rats } & No. of Trials to Reach Criterion \\
\cline { 3 - 4 } & & Mean & Range \\
\hline C & 8 & $216 \cdot 3$ & $89-431$ \\
E $_{1}$ & 8 & $264 \cdot 5$ & $125-422$ \\
$\mathrm{E}_{2}$ & 8 & $208 \cdot 3$ & $71-323$ \\
\hline
\end{tabular}

The measure obtained from weight pulling, however, showed that the administration of dieldrin had an effect on the performance of the rats. The measure considered here is running time, or the mean time taken to pull a given weight the required distance. Table 2 shows individual scores and the group means when the animals were pulling weights corresponding to 5,40 , and $50 \mathrm{~g}$. Whereas there was no significance $(P>0.05)$ in the differences between the groups when pulling a weight corresponding to $5 \mathrm{~g}$., the Jonckheere test (1954) revealed a significant trend $(\mathrm{P}<0.05)$ over the groups when 
TABLE 2

EFFECT OF DIELDRIN ON RUNNING TIME (sec.)

\begin{tabular}{|c|c|c|c|}
\hline \multirow{2}{*}{ Rat No. } & \multicolumn{3}{|c|}{ Weight Pulled } \\
\hline & $5 \mathrm{~g}$ & $40 \mathrm{~g}$. & $50 \mathrm{~g}$. \\
\hline $\begin{array}{c}\text { Group C (0 p.p.m.) } \\
7 \\
14 \\
17 \\
18 \\
20 \\
22 \\
27 \\
30\end{array}$ & $\begin{array}{r}5.0 \\
13.5 \\
5.2 \\
6.5 \\
10.4 \\
5.2 \\
1.5 \\
7.4\end{array}$ & $\begin{array}{r}6.3 \\
10.2 \\
4.4 \\
7.6 \\
9.3 \\
1.6 \\
3.3 \\
10.3\end{array}$ & $\begin{array}{r}4 \cdot 9 \\
8 \cdot 0 \\
3 \cdot 1 \\
7 \cdot 1 \\
16 \cdot 0 \\
4 \cdot 4 \\
2 \cdot 0 \\
7 \cdot 0\end{array}$ \\
\hline Mean & $6 \cdot 8$ & 6.6 & $6 \cdot 6$ \\
\hline $\begin{array}{c}\text { Group } \mathrm{E}_{1} \text { (25 p.p.m.) } \\
1 \\
4 \\
16 \\
24 \\
25 \\
26 \\
28 \\
29\end{array}$ & $\begin{array}{l}5.9 \\
2 \cdot 8 \\
3 \cdot 8 \\
5 \cdot 6 \\
4.4 \\
7.6 \\
4 \cdot 1 \\
5.8\end{array}$ & $\begin{array}{r}9.6 \\
3.9 \\
2.8 \\
8.2 \\
13.5 \\
16.6 \\
4.5 \\
7.5\end{array}$ & $\begin{array}{r}14 \cdot 3 \\
3 \cdot 1 \\
2 \cdot 9 \\
22 \cdot 2 \\
20 \cdot 0 \\
13 \cdot 1 \\
17 \cdot 2 \\
13.8\end{array}$ \\
\hline Mean & 5.0 & $8 \cdot 3$ & $13 \cdot 3$ \\
\hline $\begin{array}{c}\text { Group } \mathrm{E}_{2}(50 \text { p.p.m. }) \\
5 \\
8 \\
12 \\
13 \\
15 \\
19 \\
21 \\
23\end{array}$ & $\begin{array}{r}11.9 \\
2.5 \\
3.1 \\
4.2 \\
7.2 \\
3.3 \\
2.3 \\
3.6\end{array}$ & $\begin{array}{r}25.4 \\
3.4 \\
4.2 \\
18.3 \\
18.1 \\
11.3 \\
5.5 \\
5.9\end{array}$ & $\begin{array}{r}16 \cdot 7 \\
3.7 \\
2 \cdot 4 \\
16 \cdot 8 \\
23 \cdot 0 \\
10 \cdot 8 \\
14 \cdot 2 \\
36 \cdot 4\end{array}$ \\
\hline Mean & $4 \cdot 8$ & 11.5 & $15 \cdot 5$ \\
\hline
\end{tabular}

pulling a weight corresponding to $50 \mathrm{~g}$. Muscular efficiency was impaired; groups $E_{1}$ and $E_{2}$ gave longer running times than group $\mathrm{C}$. The deterioration in muscular efficiency was even more apparent when each animal was used as its own control, and its performance when pulling heavy weights was compared to that when pulling $5 \mathrm{~g}$. Fig. 2 shows the group means of the differences between the animals' scores for pulling $40 \mathrm{~g}$. as against $5 \mathrm{~g}$., and again the differences between pulling $50 \mathrm{~g}$. as against pulling $5 \mathrm{~g}$. Whereas the control group showed a very slight improvement on both occasions, the scores obtained for groups $E_{1}$ and $E_{2}$ showed a progressive increase. The trends with amount of dieldrin received were statistically significant (P $<0.01$ ) for both the $40 \mathrm{~g}$. and $50 \mathrm{~g}$. comparisons.

Although the deterioration in muscular efficiency was demonstrated during the course of the experiment when the rat was required to make a marked effort, none of the animals showed at any time during the entire experiment any readily observable symptoms of having received drugs.

\section{Discussion}

Muscular efficiency was defined here in terms of running time, and it was found that the administration of dieldrin increased running time progressively as the weight pulled was increased.

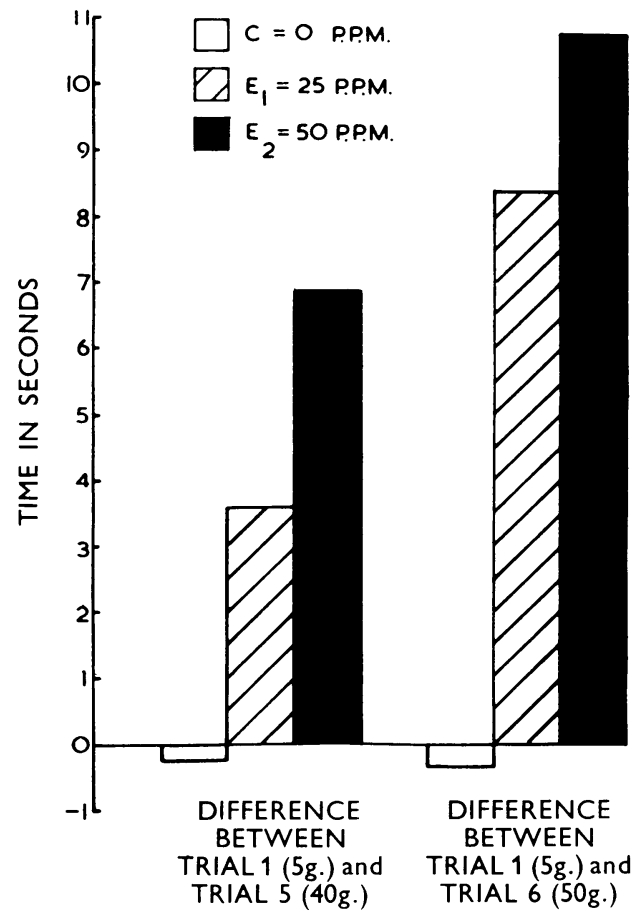

FIG. 2.-Progressive deterioration of running time due to dieldrin.

Controls showed no such deterioration, and the degree of deterioration was related to the amount of dieldrin administered. The deterioration might be due to a number of causes, for example, $(a)$ some sort of muscular incoordination, $(b)$ fatigue setting in more rapidly in the experimental animals, (c) degeneration of muscle fibres, or $(d)$ myotonia. Further experiments are required before it can be decided which of these causes produces the deterioration observed here.

Hayes (1957) mentions that it could be possible to prevent serious poisoning if the sprayers using dieldrin were removed from exposure "as soon as they reached some critical level of preclinical effects". The results obtained here suggest possible lines of investigating the early effects of dieldrin on human beings exposed to the compound, and that work is being undertaken. These investigations could lead to the detection of such a "critical level", and assist in the formulation of appropriate safety standards.

\section{REFERENCES}

Carrillo, S. J. (1954). Bol. Ofic. sanit. panamer, 37, 76. Hayes, W. J., Jr. (1957). J. trop. Med. Hyg., 31, 519.

Jonckheere. A. R. (1954). Biometrika, 41, 133

Kruskal, W. H., and Wallis, W. A. (1952). J. Amer. Statist. Ass., Patel, $47,583$. 